\title{
Overlapped Finger Geometry Signal Processing and Finger Shape Comparisons for Person Identification*
}

\author{
Ching-Liang SU \\ Department of Industrial Engineering and Technology Management, Da Yeh University \\ 112 Shan-Jeau Road, Da-Tsuen, Chang-Hua, 51505 Taiwan \\ e-mail: cls2@mail.dyu.edu.tw
}

Received: July 2006

\begin{abstract}
This study uses object-extracting technique to extract - thumb, index, middle, ring, and small fingers from hands. The algorithm developed in this study can find precise locations of fingertips and finger-to-finger-valleys. The extracted fingers contain many useful geometry features. One can use these features to conduct the person identification. Geometry descriptor is used to transfer geometry features of fingers to another feature-domain for image-comparison. Image subtraction is used to exam difference of two fingers. This study uses the fingers as features to recognize different persons.
\end{abstract}

Key words: finger shape extraction, finger shape identification.

\section{Introduction}

In the past twenty years, researchers invested a lot of effort to develop different techniques to identify hands. This past work includes - hand geometry (Hand-based biometrics, 2003; Egiazarian and Pestana, 2002; Han et al., 2003; He et al., 2002; Mitome and Ishii, 2003; Su, 2003; Sun and Qiu, 2004; Xionga et al., 2005; Xiong et al., 2005), middle finger crease pattern matching (Joshi et al., 1998), various finger size measurements (Kumar et al., 2003; Sanchez-Reillo et al., 2000), various finger lateral view size measurements (Sanchez-Reillo et al., 2000), vein pattern (Lin and Fan, 2004), eigenpalm (Lua et al., 2003), implicit polynomials (Oden et al., 2003), algebraic invariants (Oden et al., 2003), Karen invariant computation (Oden et al., 2003), line interception and slope comparisons (You et al., 2002), control point selection (Lia et al., 2003; You et al., 2002), coarse to fine strategy (Han, 2004), B-Spline (Ma et al., 2004), watershed transform (Lin and Fan, 2004), HMM (Sun and Qiu, 2004); However, some are very sensitive to the noise (Joshi et al., 1998; You et al., 2002); some have very complicated mathematical models (Oden et al., 2003) and some have very complicated neural training algorithms.

In the previous research, when performing hand geometry matching (Han, 2004; Joshi et al., 1998; Sanchez-Reillo et al., 2000), in order to recognize the hand image, every time

\footnotetext{
*National Science Council, Taiwan, supported this work under grant NSC 95-2221-E-212-003.
} 
the hand needs to place in a precise certain fixed position - thus the camera can capture the same hand image. In this study the hand needs not to place in a precise certain fixed position. Wavelet technique is used to find the finger-to-finger valley in the past research (Han, 2004; Han et al., 2003). In this study, the developed recognition algorithm automatically calculate and check the finger-edge energy response signals and selected the high energy response signals to find the finger-to-finger valleys of hand automatically. The algorithm developed in this study finds finger-to-finger valleys more accurately and more efficiently. This study amputates the finger from hand automatically and calculates the feature and shape of each individual finger separately. This study uses the amputated finger to generate more original finger features - which contain more opulent data than the finger crease pattern (Joshi et al., 1998) and rude finger shape matching methods (Han, 2004; Han et al., 2003; Sanchez-Reillo et al., 2000). Implicit polynomials are very difficult to describe finger shape by power of seven polynomial functions. In the previous research, palm-print, iris, fingerprint, face, and vein pattern (Lin and Fan, 2004) are also used to identify different persons. This study uses geometry descriptor and centroid calculation techniques to cope with image rotation and shifting problems to move fingers to same centroid and orientation for comparison - the algorithm developed in this study can be easier to identify the amputated fingers. In this study, the new technique is used to extract - thumb, index, middle, ring, and small fingers and to perform person's identification. Geometry descriptor is used to transfer geometry features of fingers to another feature-domain for image-comparison. For reducing number of finger-files in system, one person's entire fingers are placed in one file. Image subtraction is used to exam difference of two fingers. The hand are fixed each time when a picture is taken and one can assume that each time when hand image is taken, the acquired fingers are same as previous acquired ones. Since pictures are same, after fingers are extracted from the hand image, one can use acquired fingers to identify different persons.

This report consists of four sections. Section 2 describes geometry descriptor and image subtraction. Sections 3 and 4 show the test result and conclude this report.

\section{Geometry Descriptor and Image Subtraction}

Fig. 2.1 shows hands and extracted hand-edges. Fig. 2.2 shows position-features of fingertips and finger-to-finger-valleys. By using these position-features, one can extract thumb, index, middle, ring, and small fingers. The entire finger-images are shown in Fig. 2.3. The finger extracting technique is shown in reference ( $\mathrm{Su}, 2003)$.

For every pixel $g(i, j)$ in object, after the transformation of geometry descriptor, the final destination of $g(i, j)$ is $g\left(i_{f}, j_{f}\right)$. Geometry descriptor will transfer and interpolate geometry features of every pixel inside object to another feature-domain. The original geometry feature of finger will be preserved, after object is transfer to new feature-domain. In new feature-domain, every object will have same straight orientation and centroids of every object are aligned to position $(64,64)$. Since every object has same orientation and every object is aligned to same position, one can perform image subtraction to identify different fingers. 

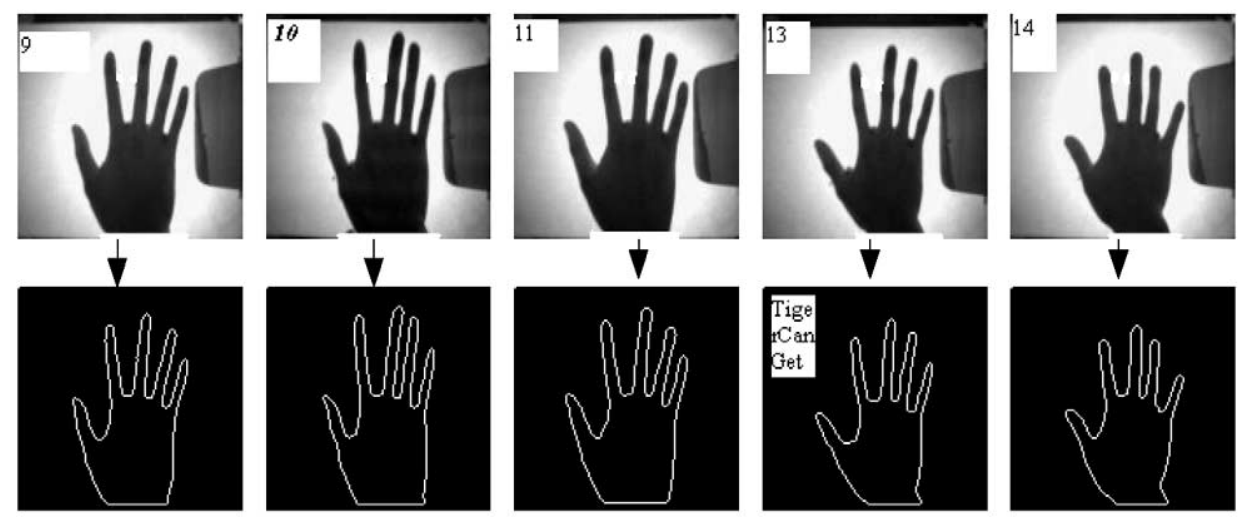

Fig. 2.1. Hands and thinned-edges of hands.

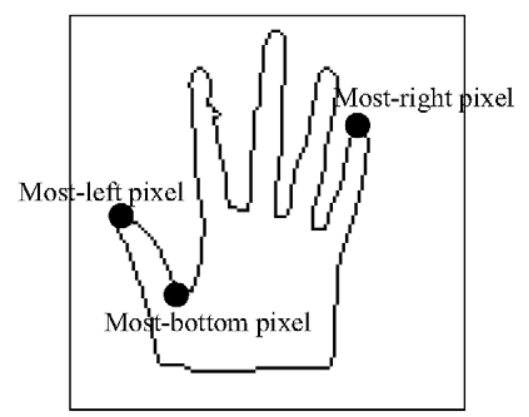

Fig. 2.2. Features of fingertips and finger-to-finger-valleys.

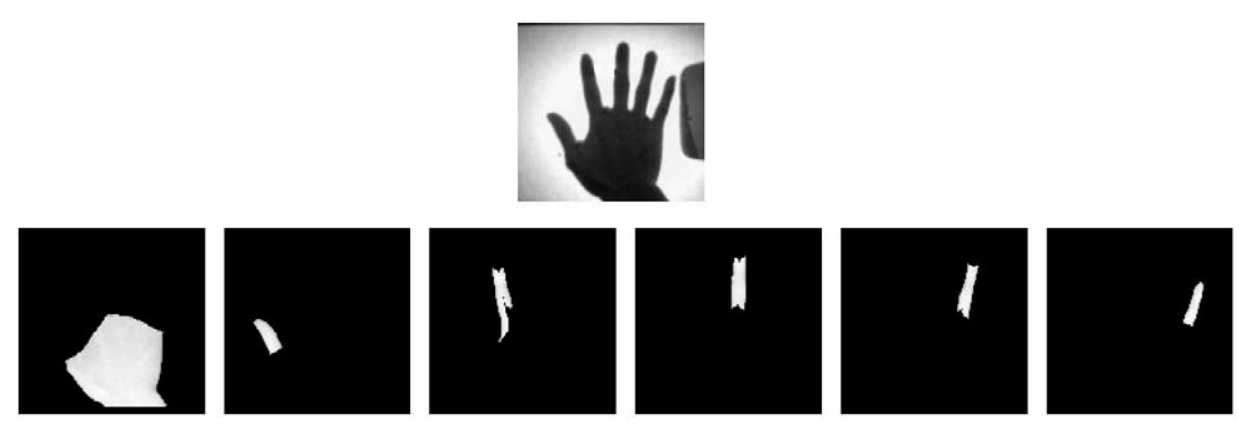

Fig. 2.3. Hand and extracted fingers.

In Eqs. 2.1 and 2.2, one supposes there is one pixel $g(i, j)$ existing inside finger. From point $g(i, j)$ to centroid of finger, one can generate one vector. By Cartesian rule, one can separate this vector to vertical and horizontal vectors. The term $i_{\text {dis } \tan c e}$ represents distance of vertical vector of a specific pixel $g(i, j)$ to centroid of finger. The term $j_{\text {dis }} \tan c e$ represents distance of horizontal vector of a specific pixel $g(i, j)$ to centroid of finger. The 
term $W e i g h t_{i j}$ represents the gray level of a specific pixel $g(i, j)$. By using Eq. 2.3, the finger's orientation can be obtained. In Eq. 2.3, the symbol $\theta$ represents the orientation of the finger and the symbol $\mathrm{Sin}^{-1}$ represents ArcSin. Images in top two rows of Fig. 2.4 show result after image descriptor is performed to the fingers.

$$
\begin{aligned}
& \operatorname{Var} 1=\sum_{j=1}^{N} \sum_{i=1}^{N}\left(i_{\text {distance }}\right)^{2} \cdot \text { Weight }_{i j}-\sum_{j=1}^{N} \sum_{i=1}^{N}\left(j_{\text {distance }}\right)^{2} \cdot \text { Weight }_{i j}, \\
& \operatorname{Var} 2=\sum_{j=1}^{N} \sum_{i=1}^{N} 2 \cdot i_{\text {distance }} \cdot j_{\text {distance }} \cdot \text { Weight } \\
& i j
\end{aligned}
$$

The bottom image in Fig. 2.4 shows overlapped geometry signals. The overlapped geometry signals are overlapped signals of - palm, thumb, index, middle, ring, and small fingers. One finger needs one file to record it. In this overlapped scheme, several fingers are recorded in one file; thus, the total number of the files in the system would be reduced. Fig. 2.5 shows various overlapped geometry signals.

During hand acquiring stage, one needs to provide illumination to hands and they are placed at different positions. Because of various illuminations to hands, the fingers present various shapes when hands are acquired. Since fingers have many different shapes, the finger-extracting system cannot precisely extract fingertip and finger-root. For coping these errors, the fingers are fine-tuned to different positions to obtain the bet-

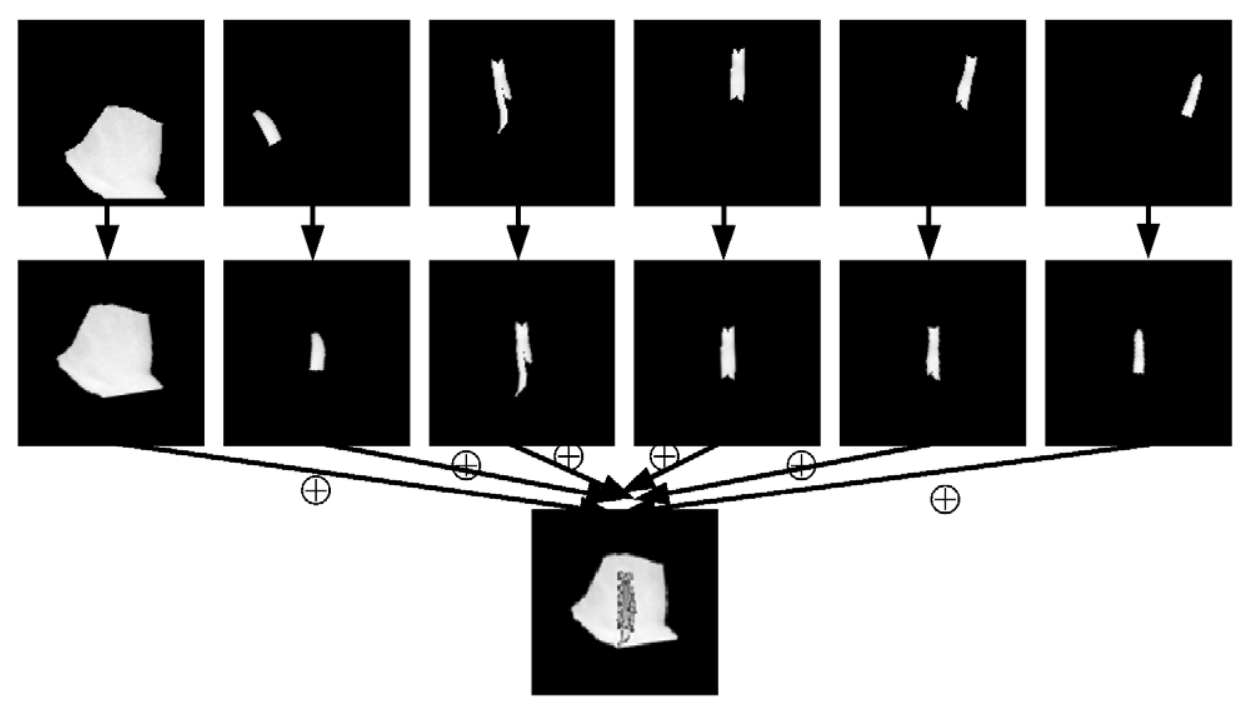

Fig. 2.4. Overlapped geometrical signal. 

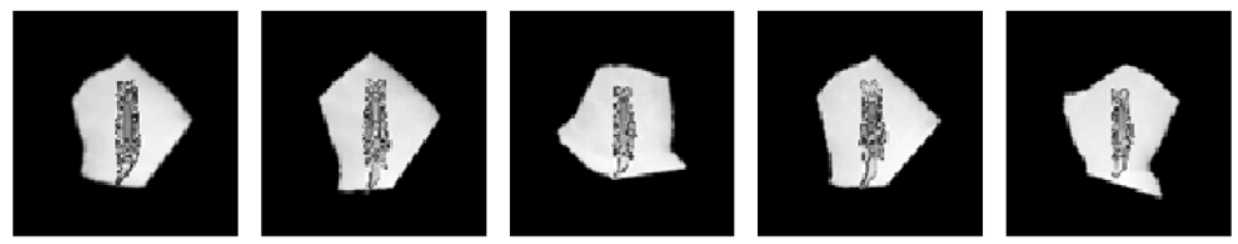

Fig. 2.5. Various overlapped geometry signals.

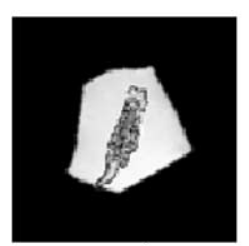

$-20^{\circ}$

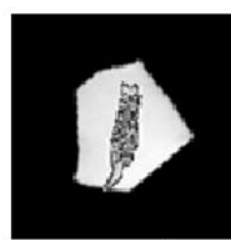

$-10^{\circ}$

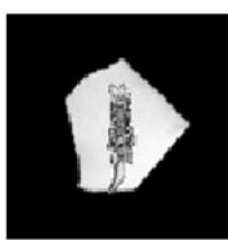

0

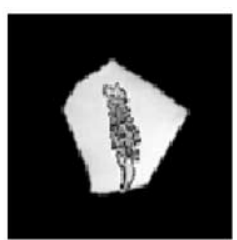

$10^{\circ}$

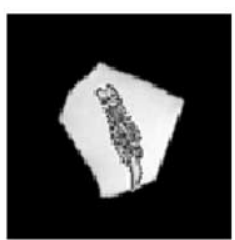

$20^{\circ}$

Fig. 2.6. Images with various orientations.

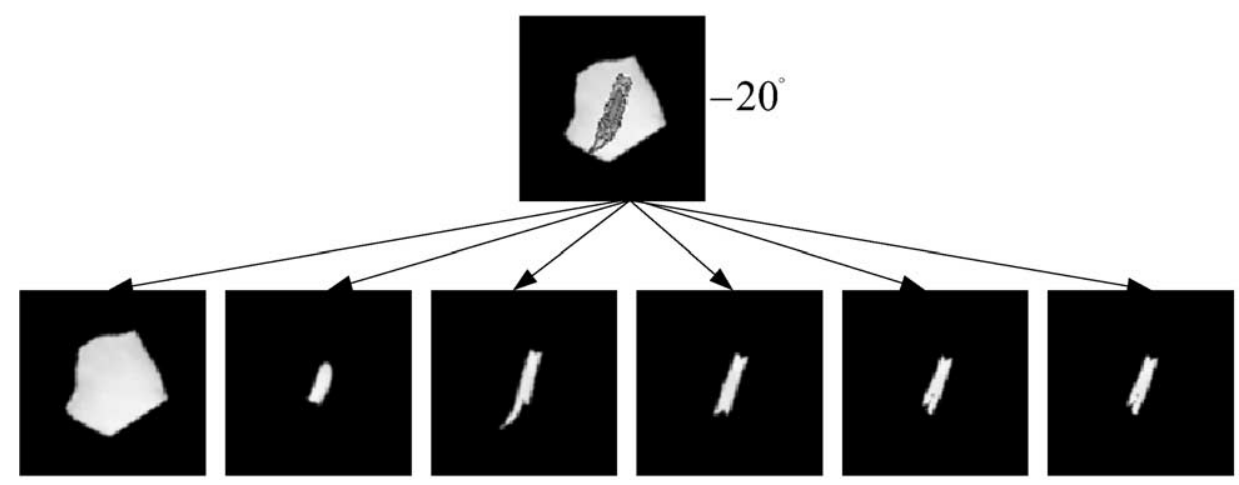

Fig. 2.7. Separating-operation to separate different fingers.

ter recognition rate. First, finger is shifted to different positions- to which are - left four pixels, left three pixels, left two pixels, etc, to right four pixels. Also, finger is shifted - top four pixels, top three pixels, top two pixels, etc, to bottom four pixels. When fingers are fine-tuned to one certain position, the finger is also fine-tuned to different orientations for comparison. The rotated degrees are - counter-clockwise 20 degrees, counter-clockwise 15 degrees, counter-clockwise 10 degrees, counter-clockwise 5 degrees, etc, to clockwise 20 degrees. Fig. 2.6 shows rotated-fingers, which are rotated from -20 degrees to +20 degrees.

As mentioned earlier, for reducing number of files in system, the entire fingers of one person are placed in one file. After finger shifting and rotation, individual finger needs to be extracted from the overlapped geometry signal separately to do the pattern recognition. The overlapped geometry signals and the extracted fingers are shown in Fig. 2.7. After obtaining individual finger, one can perform the image subtraction to fingers. Fig. 2.8 


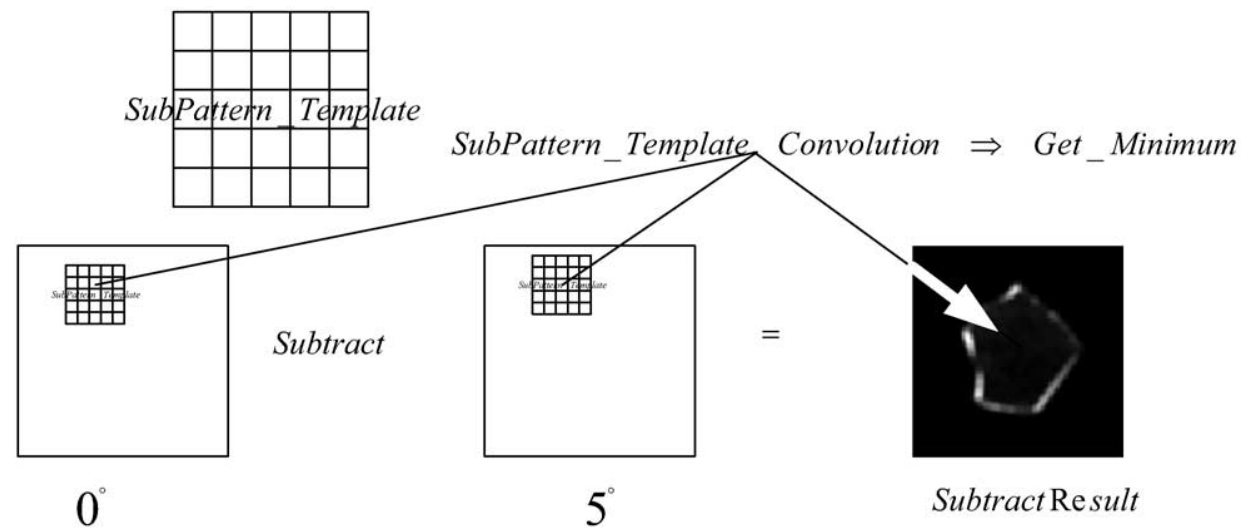

Fig. 2.8. Sub-Pattern template convolution to find minimum value.
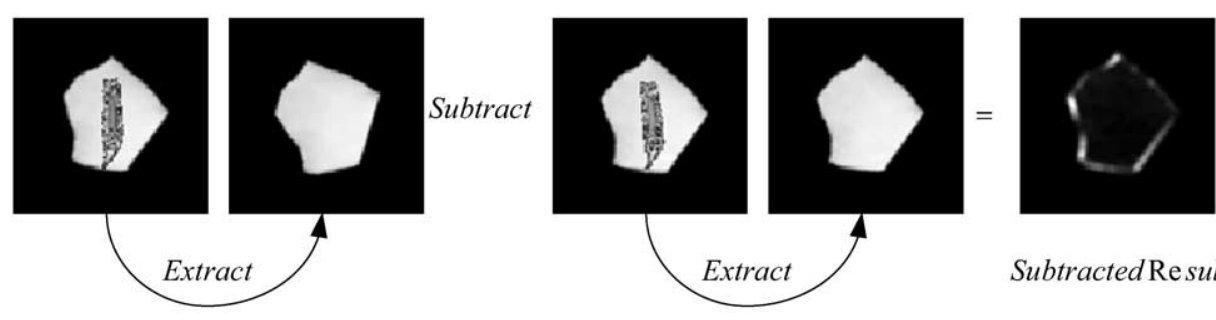

Subtracted Result

Fig. 2.9. Image-subtraction of different orientations and positions.
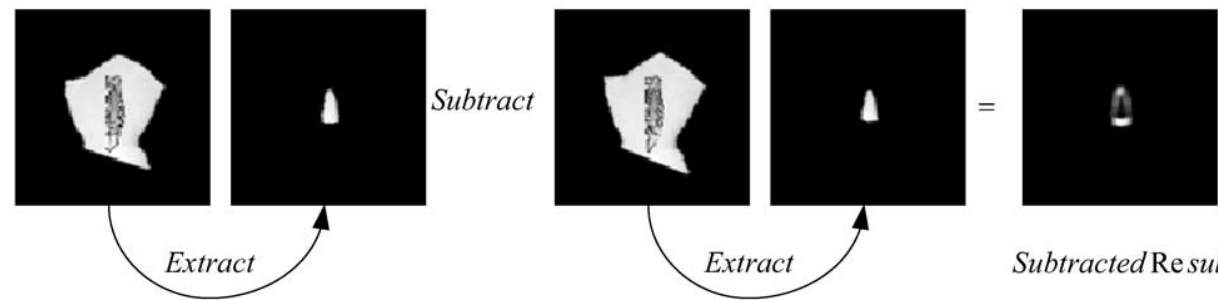

Subtracted Result

Fig. 2.10. Image-subtraction of different orientations and positions.
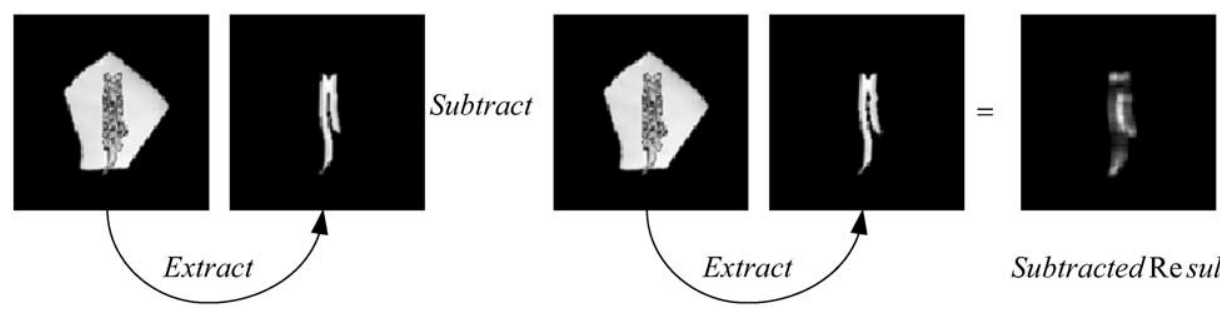

Subtracted Re sult

Fig. 2.11. Image-subtraction of different orientations and positions. 
briefly shows image subtraction scheme. The image subtractions are shown in Figs. 2.9, 2.10, and 2.11. In the top of Fig. 2.8, one can find a 5 by 5 sub-pattern template. This 5 by 5 sub-pattern template will extract the sub-pattern fingers of two persons' hands and, consequently, the image convolution is performed to these two 5 by 5 sub-pattern templates. Fine-tuning of finger is also performed in this stage and minimum value of convolution results will be recorded in resultant-image. The subtract result is shown in the right-hand side picture of Fig. 2.8. By calculating difference of subtracted-result, one can recognize different persons. In Figs. 2.9, 2.10, and 2.11, one can find the overlapped geometry signals and the extracted fingers. The image subtraction is performed to extracted fingers and subtracted-results are shown in right-hand side pictures of Figs. 2.9, 2.10, and 2.11.

\section{Results}

In this study, one person needs to place his hand at three different positions for photos taken. Totally three photos are taken for each person. In this study, hands of fifty-seven persons are taken. The illuminations are adjusted to provide different illuminations to each hand. After the hand-images are taken, several problems are found in the handimages - middle finger and ring finger of several persons are stuck or thumb finger and index finger are stretched too wide. The algorithm developed in this study cannot correctly extract the middle and ring fingers correctly when middle and ring fingers are stuck and the algorithm will not extract the wider-stretched thumb finger either. Since these two problems will cause the algorithm unable to extract the fingers, several images are discarded from the test. Actually, the hands used in this system are only one hundred and twenty, which are belonged to forty persons.

Regard these one hundred and twenty photos as whole and run these one hundred and twenty photos in one batch - which will take a very long time to get the job done. Due to the software glitch, the running process might break before the job completed. Consequently, one might endlessly run and run the procedure again and again and every time from the start. Furthermore, the database might have no enough memory to accommodate the entire obtained-data. Thus, in this system, five persons are designated as one group, i.e., five persons are regarded as a group and these five persons are tested in one batch. Since one person has been taken three different photos, totally fifteen photos are tested in each step. As mentioned earlier, in this system, there are forty persons participating the test. Thus, the system totally will run eight different batches. Totally, one hundred and twenty hands are tested. For each hand, the following steps are performed: (1) the hand edge is found, (2) the fingers are extracted separately, (3) geometry descriptor is performed to each finger, (4) image shifting and rotation are performed, (5) genuine and imposter comparisons are conducted. To each group, one photo is compared against the other 14 photos. Totally, one hundred and five comparisons are conducted to test the accuracy of the developed identification algorithm. Within those one hundred and five comparisons, fifteen comparisons are conducted for genuine-comparison, the comparisons of same person's fingers - since one person taken three different photos. The other 


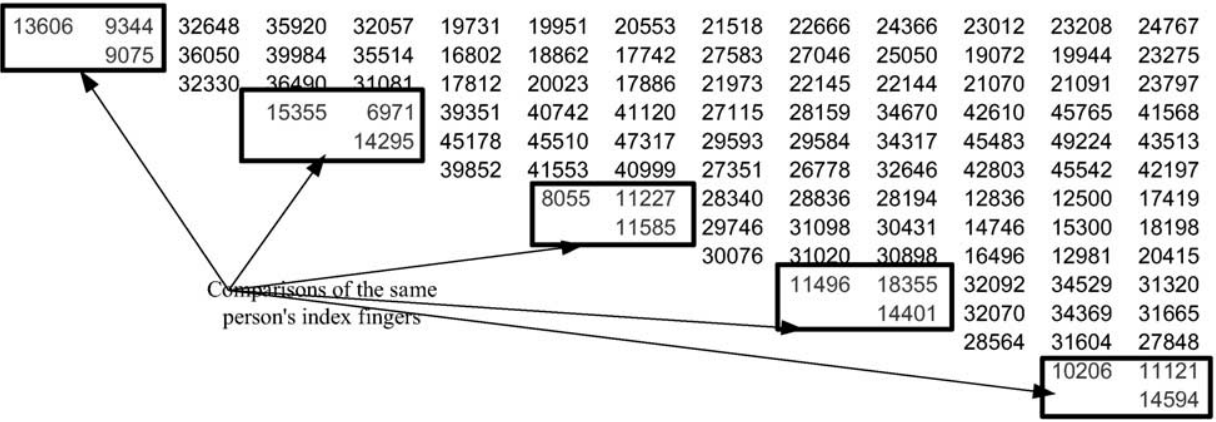

Fig. 4.1. Comparison-data of index fingers.

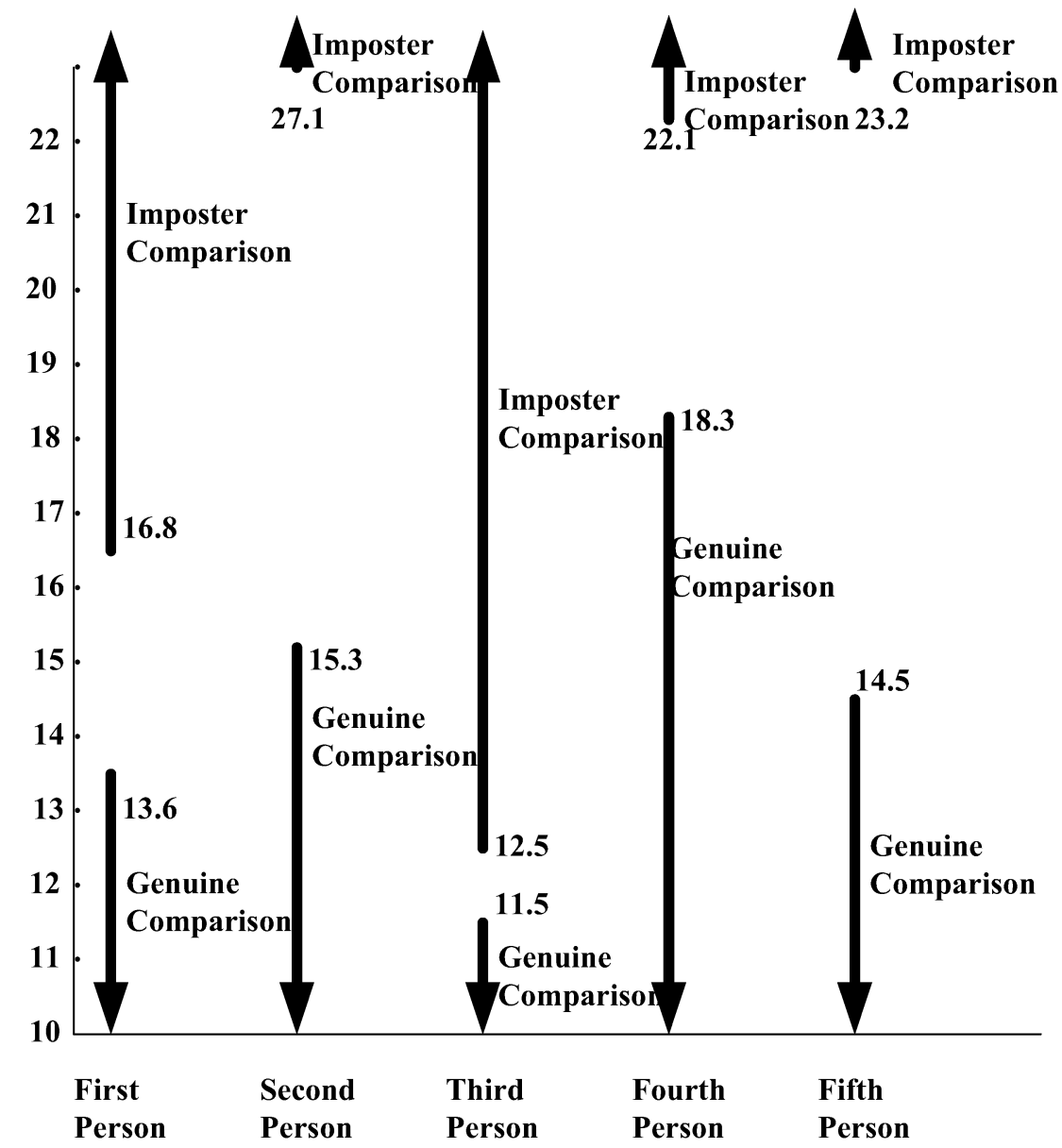

Fig. 4.2. Gap between imposter and genuine for index finger. 
ninety comparisons are conducted for imposter-comparisons - the comparisons of different person's fingers. In this study, there are eight different test batches. Thus, there are 120 genuine tests and 720 imposter tests.

\section{Conclusions}

Fig. 4.1 shows partial comparison data of image subtraction of index fingers. The data inside rectangular boxes in Fig. 4.1 is subtraction-result of one person's index finger subtracting to the same person's another index finger. The other data, which is not surrounded by rectangular boxes, show subtracted-results of differences of two different persons' index fingers. Fig. 4.2 shows summarized-results of Fig. 4.1. It shows the gap between imposter and genuine comparisons and depicts five different persons' comparison results. For each person the top line with arrow represents the value-range of imposter comparisons and the bottom line with arrow represents the value-range of genuine comparisons. By analyzing Fig. 4.2, one can conclude that the method used in this study can correctly identify persons and the accuracy rate is $100 \%$.

In this study, one also tests the other fingers. For middle finger comparison, the accuracy rate is $100 \%$. For ring finger comparison, the total false accept rate is $1 \%$ and the total false reject rate is $0 \%$. For small finger comparison, the false accept rate is $1 \%$ and the false reject rate is $1 \%$. For the thumb finger, the false accept rate is $1 \%$ and the false reject rate is $0 \%$. For the palm image the false accept rate is $0 \%$ and the false reject rate is $7 \%$.

\section{References}

Editorial (2003). Hand-based biometrics. Biometric Technology Today, 11(7), 9-11.

Egiazarian, K.O., and S.G. Pestana (2002). Hand shape identification using neural networks. The International Society for Optical Engineering, 4667, 440-448.

Han, C.-C. (2004). A hand-based personal authentication using a coarse-to-fine strategy. Image and Vision Computing, 22, 909-918.

Han, C.-C., H.-L. Cheng, C.-L. Lin and K.-C. Fan (2003). Personal authentication using palm-print features. Pattern Recognition, 36, 371-381.

He, B., Z.-D. Qiu and D.-M. Sun (2002). Secure authentication system incorporating hand shapes verification and cryptography techniques. In IEEE Region 10 Annual International Conference, Proceedings/TENCON, vol. 1. pp. 156-159.

Joshi, D.G., Y.V. Rao, S. Kar and V. Kumar (1998). Computer vision based approach to personal identification using finger crease pattern. Pattern Recognition, 31, 15-22.

Kumar, A., D.C.M. Wong and H.C. Shen (2003). Personal verification using palmprint and hand geometry biometric. In Lecture Notes in Computer Science, vol. 2688. Springer-Verlag Heidelberg. pp. 668-678.

Lia, W., D. Zhang and Z. Xub (2003). Image alignment based on invariant features for palmprint identification. Signal Processing: Image Communication, 18(5), 373-379.

Lin, C.-L., and K.-C. Fan (2004). Biometric verification using thermal images of Palm-Dorsa Vein patterns. IEEE Transactions on Circuits and Systems for Video Technology, 14(2).

Lua, G., D. Zhang and K. Wanga (2003). Palmprint recognition using eigenpalms features. Pattern Recognition Letter, 24(9-10), 1463-1467.

Ma, Y.-L., F. Pollick and W.T. Hewitt (2004). Using B-Spline curves for hand recognition. In Proceedings of the 17th International Conference on Pattern Recognition (ICPR'04). 
Mitome, A., and R. Ishii (2003). A comparison of hand shape recognition algorithms. In The 29th Annual Conference of the IEEE Industrial Electronics Society, Nov 2-6.

Oden, C., A. Ercil and B. Buke (2003). Combining implicit polynomials and geometric features for hand recognition. Pattern Recognition Letter, 24(13), 2145-2152.

Sanchez-Reillo, R., A. Sanchez and M. Gonzales (2000). Biometric identification through hand geometry measurements. IEEE Trans. Pattern Anal. Mach. Intell, 22(10), 1168-1171.

Su, C.-L. (2003). Technique for person's identification: using the extracted index finger image to identify individuals. Journal of Intelligent and Robotic Systems, 37(3), 337-354.

Sun, D.-M., Z.-D. Qiu (2004). Automated hand shape verification using HMM. In The 7th International Conference on Signal Processing Proceedings (ICSP'04). pp. 2274-2277.

Xionga, W., K.-A. Toha, W.-Y. Yaua and X. Jiangb (2005). Model-guided deformable hand shape recognition without positioning aids. Pattern Recognition, 38, 1651-1664.

Xiong, W., C. Xu and S.H. Ong (2005). Peg-free human hand shape analysis and recognition. In ICASSP. pp. 77-80.

You, J., W. Li and D. Zhang (2002). Hierarchical palmprint identification via multiple feature extraction. Pattern Recognition, 35(4), 847-859.

C.-L. Su in 1995 and 1993 respectively received his PhD and MS degrees in computer engineering from the University of Louisiana at Lafayette, USA. He received his MS degree in electrical computer engineering in 1989 from the University of Louisville at Kentucky, USA. In June 1982, he graduated from National Taipei University of Technology with a major in electronic engineering. From August 1995 to July 2000, he was working for the Department of Information Management, Oversea Chinese Institute of Technology, in Taiwan. From August 2000 up to now, he works in the Department of Industrial Engineering and Technology Management, Da Yeh University, in Taiwan.

His research interests include image processing and pattern recognition, internet database, and automated manufacturing systems.

\section{Persiklojančiu pirštu geometrijos signalu apdorojimas ir pirštų formu palyginimas asmens identifikavimui}

\section{Ching-Liang SU}

Pateikiamas ranku pirštu atpažinimo tyrimas panaudojant objektinio išskyrimo metodiką. Siūlomas algoritmas leidžia tiksliai nustatyti pirštų formų atspaudus ir tarpus tarp jų, o geometrinio aprašo pagalba palyginti gautus pirštų vaizdus ir tuo atlikti galimą asmens identifikavimą. 